\title{
Ameloglyphics - Can it Aid in Forensic Identification
}

\author{
Sugunakar Raju G S ${ }^{1}$, T Madhusudam Rao², Nandan SRK ${ }^{3}$, \\ Pavan G Kulkarni ${ }^{4}$, Shyam Prasad Reddy D ${ }^{5}$, Keerthi $\mathrm{M}^{6}$
}

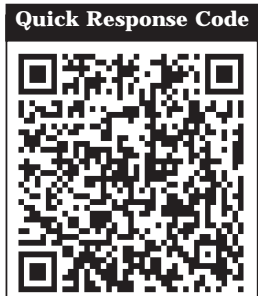

doi: $10.5866 / 2014.641669$

1Post Graduate Student

${ }^{2 \& 4}$ Reader

${ }^{3}$ Professor and HOD

${ }^{5 \& 6}$ Senior Lecturer

Department of Oral and maxillofacial pathology,

Kamineni Institute of Dental Sciences,

Sreepuram, Narketpally, Nalgonda-508254.

\section{Article Info:}

Received: J uly 8, 2014

Review Completed: August 9, 2014

Accepted: November 10, 2014

Available Online: J anuary, 2015 (www.nacd.in)

(C) NAD, 2015 - All rights reserved

Email for correspondence:

sugudenzy@gmail.com

\begin{abstract}
:
Context: Personal identification methods may not be efficient when bodies are decomposed, burned, in cases where only small fragments of calcified tissues such as bone and teeth are left. Enamel is the hardest calcified tissue in the human body consisting of numerous undulating and intertwining enamel rods. Macroscopically, incremental pattern of enamel rods is exhibited on tooth surface as perikymata, but microscopically, groups of enamel rods run in unique direction, which differ from adjacent group of enamel rods and results in forming different patterns of enamel rod endings on tooth surface. Ameloglyphics is the study of enamel rod end patterns on tooth surface.
\end{abstract}

Aims: To analyze and assess enamel rod patterns in establishing identity of an individual.

Settings and Design: 30 freshly extracted teeth of different age groups and sex had been subjected to acid etching using $10 \%$ orthophosphoric acid for taking impression of enamel rod end pattern using cellophane tape.

Materials and methods: 30 freshly extracted teeth (15 male and 15 female) are taken and fixed in $10 \%$ formalin. Further they are subjected to scaling to remove any calculus and stain remnants after which the middle third central portion of the tooth is etched with $10 \%$ orthophosphoric acid. Later by using cellophane tapethe imprint of etched area is taken and mounted on to a glass slide. The photomicrographs of these impressions were taken under 40X magnification using light microscope and digital camera; later these photomi crographs were subjected to Verifinger standard SDK version 5.0.

Statistical analysis: The interpretations of photomicrographs using verifinger software werestatistically analyzed for knowing pattern differences in males and females.

Results: The samples showed definite enamel rod end patterns which werespecific for an individual and al so specific for a tooth.

Conclusion: Tooth imprint technology (Ameloglyphics) lays additional investigative avenues in personal identification during forensic investigations especially in severe burnt and deceased cases.

Key words: Ameloglyphics, Orthophosphoric acid, Verifinger standard SDK version 5.0.

\section{Indian Journal of Dental AdVAncements}

Journal homepage: www. nacd. in 


\section{INTRODUCTION}

I dentification of a person either dead or alive is most important in forensic investigations. It is usually achieved by the use of passwords, physical tokens, photographs, iris and dental patterns, fingerprints and more recently, DNA analysis. ${ }^{1}$ These methods are not useful in cases where the bodies are totally decomposed or burnt, where only remnants of calcified tissues such as bone and teeth fragments are evident.

Tooth is composed of enamel, dentin, pulp and cementum of which enamel and dentin are highly calcified structures in the body that resist decomposition. Development of enamel is a complex organized process, where the amel oblasts lay down the enamel rods in an undulating and inter-twining path. Macroscopically, incremental pattern of enamel rods is exhibited on tooth surface as perikymata, but microscopically, groups of enamel rods run in unique direction, which differ from adjacent group of enamel rods and results in forming different patterns of enamel rod endings on tooth surface. 2,3,4 The study of these enamel rod end patterns is called as ameloglyphics, this term was given by manjunath et al. ${ }^{5}$

Biometrics refers to identification of individuals using biological traits, such as those based on retinal or iris scanning, fingerprints, or faces recognition. Verifinger ${ }^{\circledR}$ standard SDK version 5.0 is biometric software designed to compare and analyze finger prints. Liza et al used the same software for automated biometric study of Hunter Schreger bands in enamel for personal identification. ${ }^{6}$

The present study was carried out to establish identity of an individual based on ameloglyphics.

\section{Materials and Methods:}

30 freshly extracted teeth (15 male and 15 female) aretaken and fixed in 10\% formalin, of these some of the teeth were collected from different individuals and some from the same individual for inter-individual and intra-individual comparison.

\section{Exclusion criteria:}

Teeth with decay, attrition, abrasion, erosion, hypoplasia, fracture and/ or restorations were not selected for the study.

The formalin fixed teeth were washed and subjected to scaling for removal of any calculus and stain remnants, after which the middlethird central portion of the tooth is etched with $10 \%$ orthophosphoric acid for 20 seconds followed by washing with distilled water and allowed it to dry. F urther the etched area is subjected to acetone wash for removal of left over moisture, and aids in completedryness. Followed by it a strip of cellophane tape is adhered on to the etched surface and kept it for 15 minutes, a piece of cotton is used to rub the tape over the etched surface for better adaptation and proper collection of impression of enamel rod end patterns. Later the strip of cellophane tape holding imprint of dry etched area is taken and mounted on to a glass slide (Figure 1 and 2).

The photomicrographs of these imprints were taken under 40X magnification using light microscope and digital camera shown in figure.3; later these photomicrographs were subjected to Verifinger standard SDK version 5.0 software, which generated different tooth imprint patterns (Figure 4 and 5).

\section{Results:}

None of the 30 tooth prints obtained showed distinct similarity to each other either in the same individual but different teeth fpremolar(44)premolar(34)\} or in different individual but same teeth \{incisors(31)\}.

Each tooth print generated by the software was composed of series of lines representing arrangement of enamel rod ends on surface of tooth. These lines were seen running in varying directions giving to a distinct sub-pattern. In the present study on analysis of the total sample of tooth prints yiel ded 8 distinct sub-patterns namely wavy-branched, wavy-unbranched, linear-branched, linearunbranched, whorl-open, whorl-closed, loop and stem-like (Table 1 and 2; Graph 1 and 2).

\section{Discussion:}

Forensic odontology is considered to be a specialised and reliable science for identification of the deceased, particularly in multiple fatality incidents. The practice of this discipline was first introduced by Dr. Oscar Amoedo (Father of Forensic Odontology), who identified the victims of fire accident in Paris, Francein 1897. ${ }^{7}$ In mass disasters particularly in fire accidents where there is no evidence of soft tissues remnants, identification is based on hard tissue remnants like teeth and bone. ${ }^{8}$ 
Table 1: Distribution of different enamel rod end patterns in total sample size

\begin{tabular}{lc} 
Enamel rod end Patterns & No.of subjects \\
Wavy Branched (WB) & 11 \\
\hline Wavy Un-branched (W-Ub) & 4 \\
\hline Linear Branched (LB) & 6 \\
\hline Linear Un-branched (L-Ub) & 2 \\
\hline Whorl Open (Wh-O) & 2 \\
\hline Whorl Closed (Wh-C) & 1 \\
\hline Loop (L) & 2 \\
\hline Stem Like (SL) & 2 \\
\hline
\end{tabular}

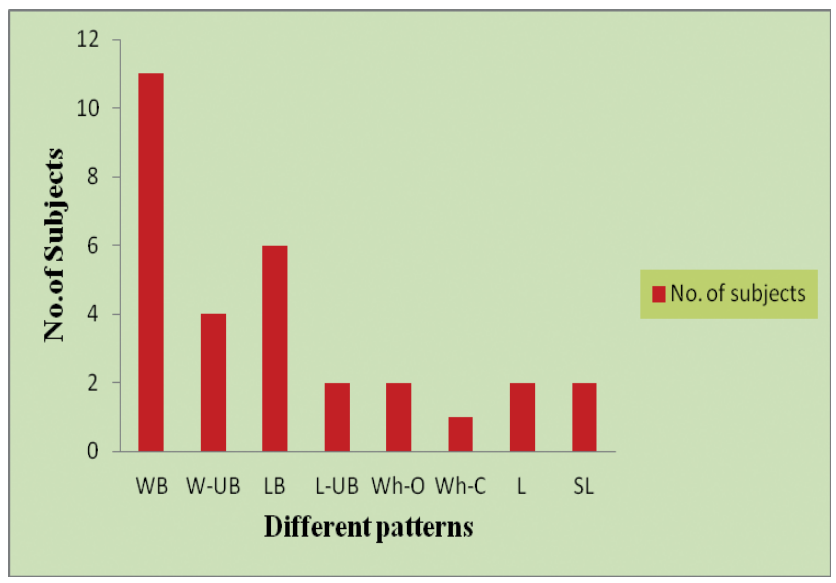

Graph 1: Distribution of different enamel rod end patterns in total sample size

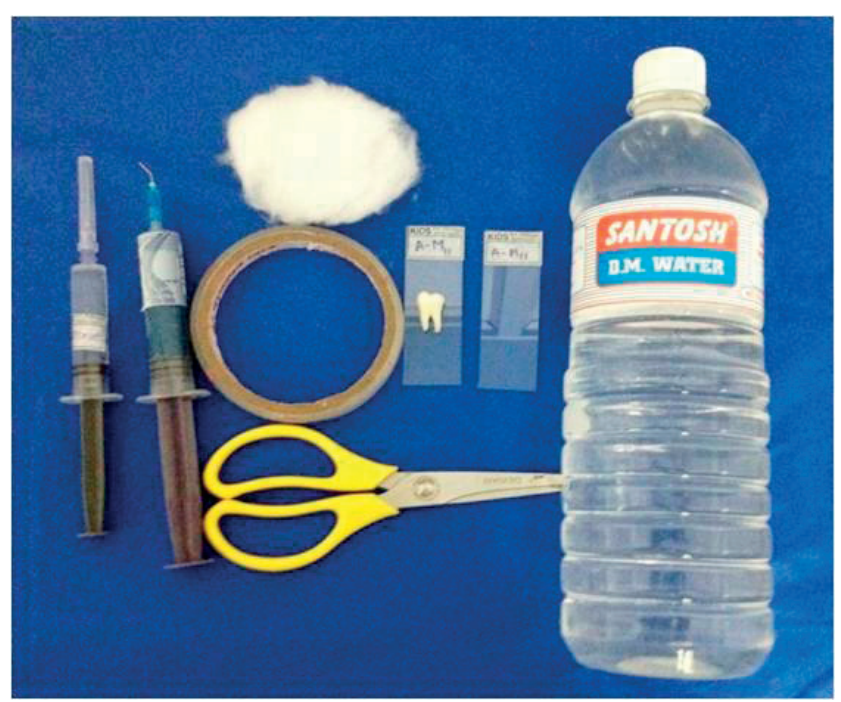

Figure 1: Different materials used for recording tooth imprints
Table 2: Distribution of different enamel rod end patterns in males and females

\begin{tabular}{lcc} 
Enamel rod end Patterns & Male & Female \\
Wavy Branched (WB) & 5 & 6 \\
\hline Wavy Un-branched (W-Ub) & 2 & 2 \\
\hline Linear Branched (LB) & 4 & 2 \\
\hline Linear Un-branched (L-Ub) & 1 & 1 \\
\hline Whorl Open (Wh-O) & 2 & 0 \\
\hline Whorl Closed (Wh-C) & 1 & 0 \\
\hline Loop (L) & 1 & 1 \\
\hline Stem Like (SL) & 2 & 0 \\
\hline
\end{tabular}

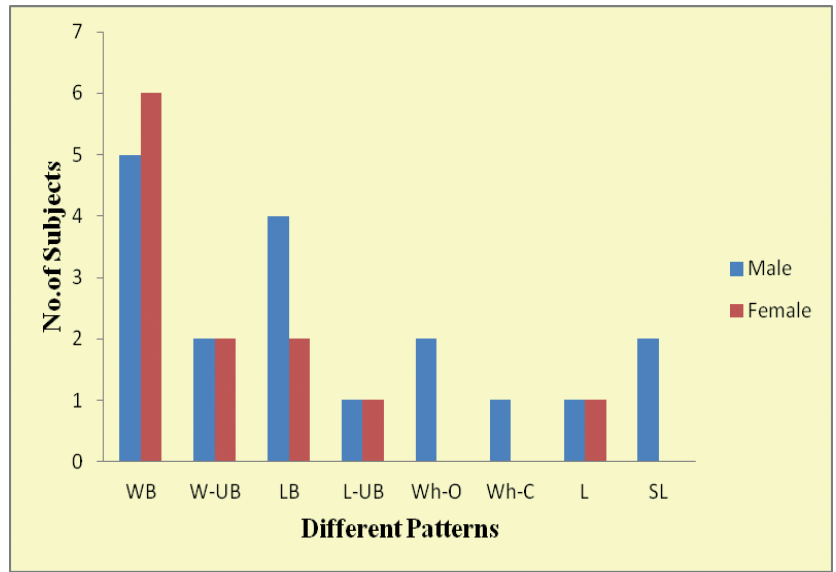

Graph 2: Distribution of different enamel rod end patterns in males and females

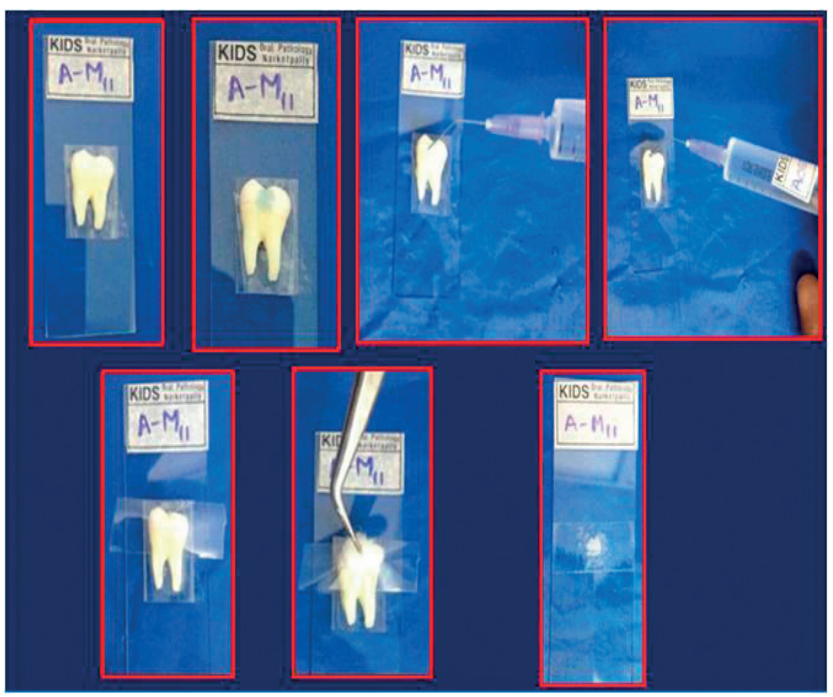

Figure 2: Different steps in procedure of collecting tooth imprints 


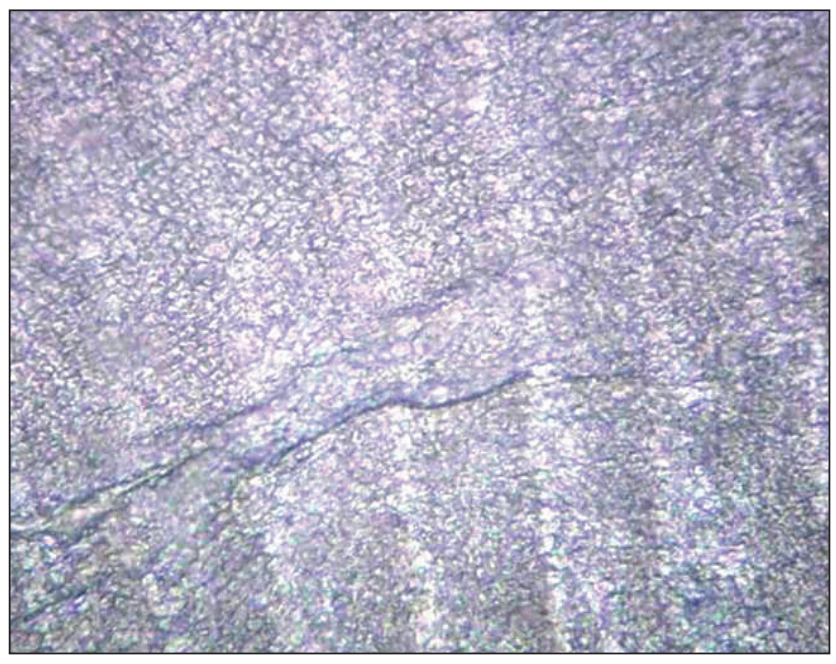

Figure 3: Figure 3: Photomicrograph of enamel rod end pattern under 40X magnification

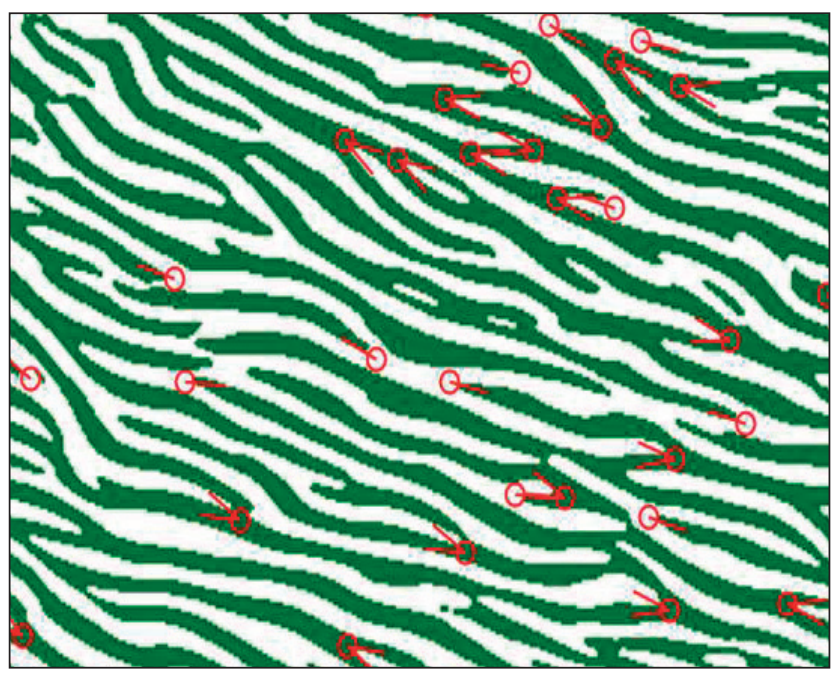

Figure 5: Tooth imprint pattern generated by Verifinger software.

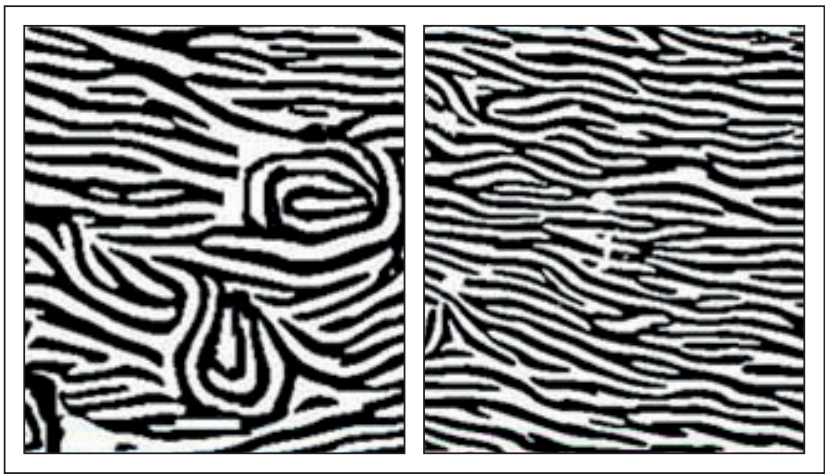

Figure 7: Intra individual variation in tooth imprints $(34,44)$ of a person

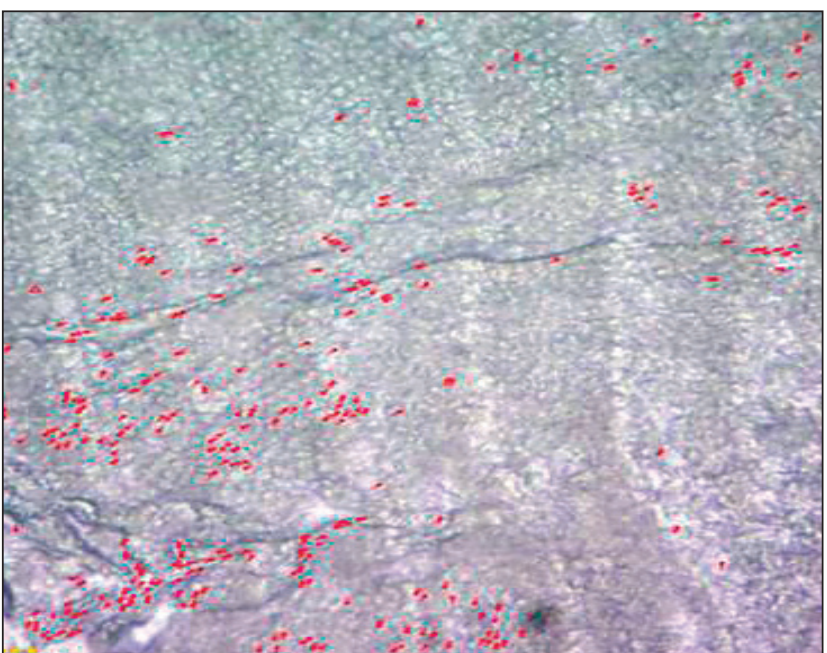

Figure 4: Photomicrograph of enamel rod end pattern subjected to Verifinger software.

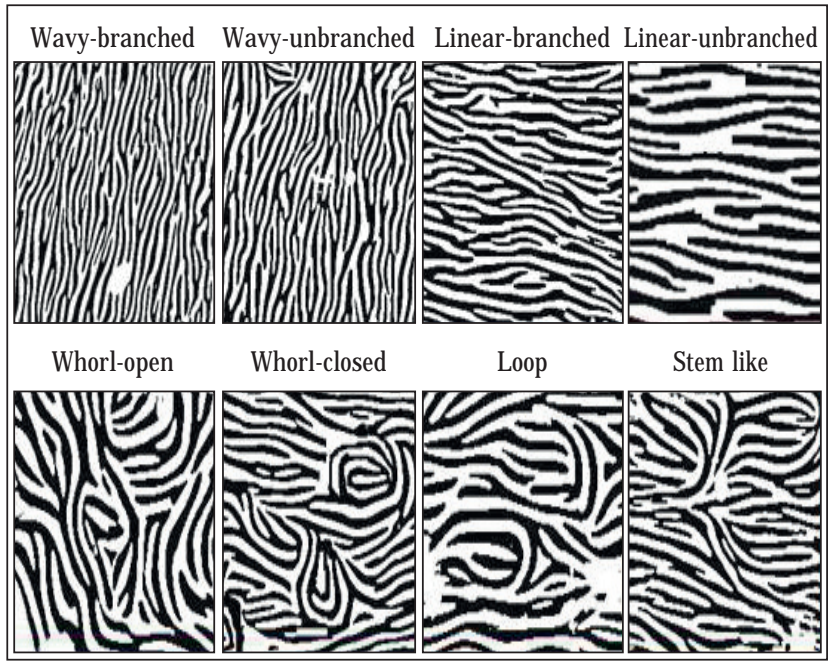

Figure.6: Different Tooth imprint patterns generated by Verifinger software.

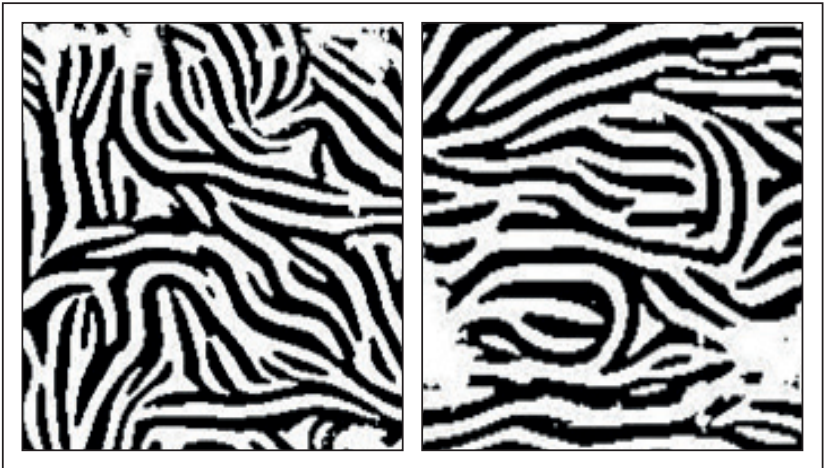

Figure 8: Inter individual variation in tooth imprints (31) of a person. 
Teeth are considered to be the most indestructible components of the human body, which have the highest resistance to most environmental effects like fire, desiccation, and decomposition. Enamel is the hardest substance in the body. ${ }^{9,10}$ The undulating course of ameloblast during amelogenesis results in the formation of a specific pattern by so, the course of enamel rods is not the same throughout the thickness of enamel. ${ }^{3}$ These series of lines running in various directions forming various sub-patterns which were unique to individual tooth. These patterns on the enamel surface are called as tooth prints. The study of enamel rod end patterns on tooth surface is termed as ameloglyphics. ${ }^{11}$

In the present study, results showed that the tooth prints exhibited a pattern of lines that represents the endings of series of adjacent enamel rods and every tooth imprint is unique to a particular tooth, as well as particular to an individual. Analysis of the 30 tooth prints yielded 8 distinct sub-patterns namely wavy-branched), wavyunbranched, linear-branched, linear-unbranched, whorl-open, whorl-closed, loop and stem-like. The present study showed similar results in accordance with the study conducted by Manjunath et al.

In comparsion of tooth prints with that of the finger prints, this is composed of a single distinct pattern like whorl, loop or arch. Whereas a tooth print is composed of combination of basic subpatterns.

In the present study to know the uniqueness of tooth prints, a intra and inter individual comparsion was made, which showed that tooth prints were unique to an individual, exhibiting dissimilarity both between teeth of different individuals and of the same individual. As this technique is simple, inexpensive, rapid and can also be performed by nonprofessionals. Along with these advantages, the uniqueness of the tooth print can serveas a valuable tool in forensic science for personal identification.

\section{Conclusion:}

Enamel is the hardest substance in the body, though it is hardest the surface of enamel is al ways subjected to both micro and macro-wearing. The effect of processes likeabrasion, attrition and erosion are to be considered as they wears the outermost layer of enamel rod ends, and exposes the underneath layer. ${ }^{12}$ Secondly, the enamel rods do not traverse the whole length of enamel in a straight path. Instead, they traverse in undulating and intertwining path, so the course of enamel rods is not same throughout the thickness of enamel..$^{13}$ Hence the difference in the depths of enamel rod end arrangement needs to be verified by further studies.

Even though tooth prints are unique to an individual tooth, the value of it as a tool in forensic science for personal identification depends on its reproduction and permanency. Further studies are required to explore its significance in personal identification.

\section{References:}

1. Weicheng S, Tieniu TJ . Automated biometrics-based personal identification. Proc Natl Acad Sci USA 1999; 24:11065-11066.

2. Berkovitz BK, Holland GR, Moxiham BJ. Enamel. In: Berkovitz BK, Holland GR, Moxiham BJ, editors. Oral Anatomy, Histology and Embryology. 3rd Ed. London, Mosby publ; 2002 pg 110-111.

3. Osborn J W. Directions and interrelationships of enamel prisms from the sides of human teeth. J Dent Res 1968; 47:223-232.

4. Boyde A. Amelogenesis and the structure of enamel. In: Cohen B, Kramer IR, editors. Scientific foundations of dentistry. London, William Heinemann Medical books Ltd, 1976 pg 341-343.

5. Manjunath K, Sriram G, Saraswathi TR, Sivapathasundharam B; Enamel rod end patterns: a preliminary study using acetate peel technique and automated biometrics; J Forensic Odontol; 2008; 1(1):32-36.

6. Liza L, Ramenzoni, Sergio RP. Automated biometrics-based personal identification of the hunter schreger bands of dental enamel. Proc Royal Soc B 2006; 273:1155-1158.

7. Delattre VF. Burned beyond recognition: Systematic approach to the dental identification of charred human remains. J Forensic Sci 2000; 45:589-596.

8. Rotzscher K, Grundma C, Benthaus S. The effect of high temperatures on human teeth and dentures. Int Poster J Dent Oral Med 2004; 6:1-4.

9. Stefen C. Enamel structure of arctoid carnivora: Amphicyonidae, Ursidae, Procyonidae and Mustelidae. J Mammal 2001; 82:450-452.

10. Holland MM, Cave CA, Holland CA, BilleTW. Development of a quality, high throughput DNA analysis procedure for skel etal samples to assist with the identification of victims from the World Trade Center att acks. Croat Med J 2003; 44:264-265.

11. Manjunath K. Enamel rod end patt erns: A preliminary study using acetate peel technique and automated biometrics. J Forensic Odontol 2008; 1:33-36.

12. Roberson TM, Heymann HO, Swift EJ J r. Sturdevant's art and science of operative dentistry. (4th edn), Mosby, 2002 pg 411-412.

13. Gaunt WA, Osborn J W, Ten Cate AR. Advanced dental histology. (2nd edition), Bristol J ohn Wright, 1971 pg 95-96. 